\title{
Common ground in engineering geology, soil mechanics and rock mechanics: past, present and future
}

\author{
Helmut Bock
}

Published online: 4 August 2006

(C) Springer-Verlag 2006

\section{Bull Eng Geol Environ (2006) 65(2):209-216}

It has come to the Editor's attention that in the paper Common Ground in Engineering Geology, Soil Mechanics and Rock Mechanics: Past, Present and Future (Vol 65, No 2, p. 215) Bock's quotation of Fookes (QJEG, 1997, Vol 30, 293-424) is incorrect, possibly due to translation differences.

Bock's short quotation states “engineering geology's role... is essentially that of a service agent". In the Abstract to his 1997 paper, however, Fookes actually says "The current status of development in engineering geology on a parochial and world scene is briefly judged. At present engineering geology is largely seen as a service profession, but the potential for developments in understanding the earth and earth's processes for the benefit of mankind through engineering is exciting. Engineering geology should not lose its distinct role but communication and interaction with engineering needs fostering."

In the 1997 paper Fookes also provides a schematic relationship between civil engineering, geotechnology and geomaterials to illustrate his view on the interactive relationship with sister disciplines (his Fig. 6, p. 302), which is not unlike Figs. 4 and 6 of Bock's paper. Fookes argues (p. 293) that "The engineering geological environment of the site includes the geological history and the current geomorphological process and climatic conditions. The development of the geological model for any site therefore requires specific consideration of the regional and local geological and geomorphological history and current ground surface conditions."
The online version of the original article can be found at http://dx.doi.org/10.1007/s10064-005-0020-3

H. Bock $(\bowtie)$

Q+S Consult, International Consulting for Quality Control and Safety Management in Geotechnical Engineering, Stoltenkampstr. 1, 48455 Bad Bentheim, Germany

e-mail: QS-Consult@t-online.de 